\title{
Abusive patients: Is it time for accountability?
}

$\mathrm{S}$ lapped, pinched, punched, groped, sworn at and spat on: many health workers have had enough. Increasingly they're urging zero tolerance for the routine violence they face on the job. But what happens when the abuse comes from a patient who still needs care? Emerging efforts to monitor and hold patients accountable for violence may answer these and other questions.

Historically, health organizations have blamed the victims for failing to manage patients' bad behaviour. Dr. Robert Swenson, chief of psychiatry at the Ottawa Hospital, recalls the guilt he felt following an attack by a female patient early in his career. "She was kept in the hospital and transferred to another doctor, and that felt like confirmation that I was the problem, when in fact she was fully responsible."

It has been at least two decades since workplace violence was identified as an "emerging hazard" in health care, yet Swenson's experience is still a common one. In Ontario, health workers make up $10 \%$ of the labour market, yet suffer $30.6 \%$ of injuries from workplace violence that result in time off. Nurses are more likely to be attacked at work than prison guards or police officers. The frequency of abuse is also alarming: in a 2014 Emergency Nurses Association study, participants experienced an average of six violent incidents in an 18-month period.

At the root of the problem is a persistent belief that abuse must be tolerated as "part of the job," explains Irene Andress, chief nursing executive at the Michael Garron Hospital in Toronto. "Most organizations are sitting under a cloak of secrecy where people are very reluctant to report violence in the workplace."

\section{Patient flagging}

At Michael Garron, identifying patients who pose a risk of violence has helped to communicate zero tolerance, Andress says. Patients with his-

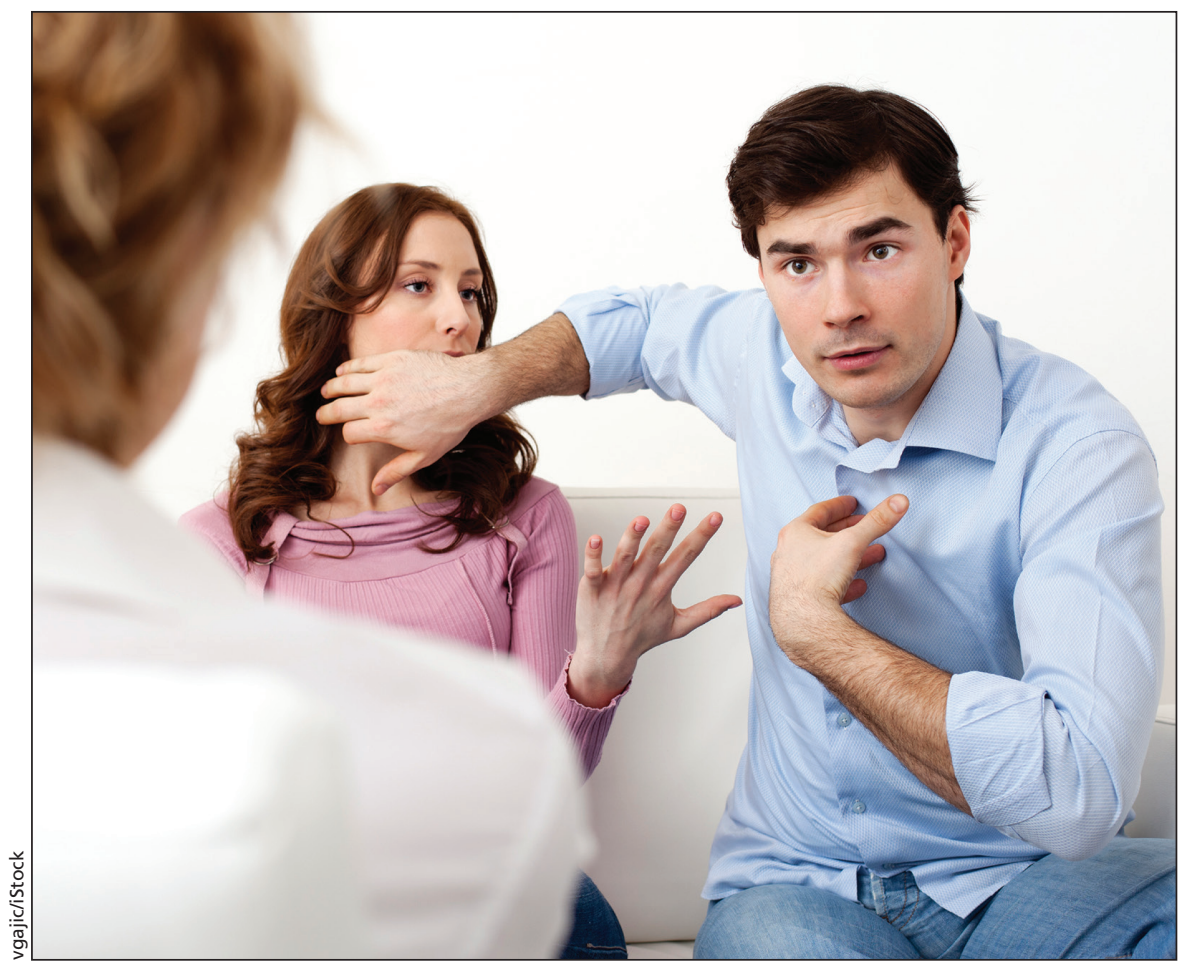

Identifying patients who pose a risk of violence is one way health facilities are protecting staff.

tories of abusive behaviour or who show "signs of escalating behaviour" wear identifying coloured bracelets and have "flags" added to their electronic medical records.

Patient flagging, combined with deescalation training and alarm devices for staff, has helped Michael Garron reduce the percentage of incidents in which "use of force" was necessary to contain a threat from $30 \%$ in 2007 to $8.9 \%$ in 2015. Andress also notes that staff confidence in the hospital's commitment to safety has increased, along with reporting of abuse, suggesting that incidents were previously underreported.

"This is no different than when a patient is flagged for falls or pressure ulcers or having some kind of infection," she says. "We put you in a particular environment. We wear gloves and masks. Why should we manage violent situations any differently?"

Flagging patients who may pose a risk but don't have records of violence is becoming a leading practice, says Henrietta Van hulle, an executive director for Ontario's Public Services Health and Safety Association (PSHSA). Michael Garron Hospital is one of a handful of institutions in Ontario using this approach, including Hotel Dieu Hospital in Kingston, Ont. and the Ottawa Hospital.

According to Van hulle, the main drawback to any kind of flagging is the potential for discrimination against marked patients. There is also still "some grey zone" when it comes to defining escalating behaviours. For example, should a raised voice or demanding attitude merit a flag? "You can't put flagging in place without really hitting some of these issues with front-line staff," Van hulle says.

PSHSA will soon release a flagging handbook and risk-assessment checklist to clarify which behaviours should be considered before applying a flag, who to involve in the decision, as well 
as when to revisit and remove the warnings.

At Michael Garron, flags stay on file indefinitely, but could be reviewed on a case-by-case basis, says Andress. She acknowledges that flagging can have a "negative connotation," but denies that it could lead to lower-quality care for difficult patients. "We're not using this to create a black mark against the individual," she says. "It gives us history and context."

\section{Stronger sanctions}

Physicians are also advocating for more serious legal consequences for patients who attack health workers. Last year, the Canadian Medical Association, General Council passed a motion $89 \%$ in favour of lobbying the federal government for specific Criminal Code protections for health workers, similar to the special penalties for assaults on police officers and public transit operators. A small group will suggest action to the CMA board, although no timelines have been set.

"Violence, which has been ubiquitous, does not need to be tolerated," says Dr. Gary Chaimowitz, head of forensic psychiatry at St. Joseph's Healthcare in Hamilton, who led the CMA motion. Stronger sanctions could deter "the part of violence that has a willful component," he explains.

Patients seldom face charges for assaults on health workers because it's assumed they cannot control their actions when impaired by distress, illness, drugs or alcohol. The reality is less clear cut, says Chaimowitz, who sits on Ontario's Consent and Capac- ity Board. "We know that people make decisions about who they strike and they are more likely to strike at someone who can't respond," which is why workers lower in the health care hierarchy bear the brunt of abuse.

The Ottawa Hospital's Swenson seconded Chaimowitz's motion at the CMA meeting. Excluding some extreme cases, he argues that most patients are "capable of understanding and forming intent and would be deterred by a more severe penalty for attacking health care providers."

Determining who should be held criminally responsible for their actions ultimately isn't a health care decision, Swenson adds. "It's a police and judicial decision." — Lauren Vogel, CMAJ

CMAJ 2016. DOI:10.1503/cmaj.109-5266 